\title{
Pulmonary artery obstruction caused by a rare type of primary cardiac synovial sarcoma
}

\author{
Qiuzhe Guo, MD, ${ }^{\mathrm{a}}$ Chunyan Lu, MD, ${ }^{\mathrm{b}}$ and Yingqiang Guo, $\mathrm{MD}^{\mathrm{a}}$
}

Video clip is available online.

A 17-year-old male presented to our hospital for recurrent episodes of syncope. A preoperative transthoracic echocardiogram showed a giant mass in the main pulmonary trunk causing obstruction of the pulmonary artery while protruding into both the right and left pulmonary arteries (Figure 1, A). Cardiac magnetic resonance imaging (MRI) confirmed a clear-border giant mass located in the main pulmonary trunk and the 2 pulmonary arteries. The MRI signal was isointense to myocardium on T1-weighted imaging and hyperintense on both $\mathrm{T} 2$-weighted and fat-supression images (Figure 1, $B$ and $C$ ). Diffuse, mild enhancement of the tumor

From the Department of Cardiovascular Surgery ${ }^{\mathrm{a}}$ and the Department of Radiology, West China Hospital, Sichuan University, Chengdu, Sichuan, China.

Disclosures: Authors have nothing to disclose with regard to commercial support. Received for publication Feb 8, 2013; accepted for publication Feb 27, 2013; available ahead of print April 18, 2013.

Address for reprints: Yingqiang Guo, MD, Department of Cardiovascular Surgery, West China Hospital, Wai nan guo xue Rd 37th, 610041, Chengdu, Sichuan, PR China (E-mail: drguoyq@hotmail.com).

J Thorac Cardiovasc Surg 2013;146:980

$0022-5223 / \$ 36.00$

Copyright (c) 2013 by The American Association for Thoracic Surgery http://dx.doi.org/10.1016/j.jtcvs.2013.02.053 as well as dynamic pulmonary obstruction was noted in MRI contrast-enhanced images (Figure 1, $D$ and $E$, and Video 1). This patient underwent an operation and the tumor was resected from the pulmonary artery (Figure $1, F$ ). Pathologic examination confirmed a primary cardiac synovial sarcoma with SS18 gene translocation.

Primary cardiac tumors are uncommon conditions (incidence in autopsy series ranges only from $0.001-0.03 \%$ ), with the occurrence of a malignant neoplasm $<25 \%{ }^{1}$ Cardiac sarcomas account for the majority of this primary malignancy, which is usually found in the atrium and ventricle. ${ }^{2}$ A primary cardiac synovial sarcoma located in the pulmonary artery is extremely rare. This report highlights the importance of cardiac MRI in confirming the presence of a space-occupying lesion, localizing it, assessing the extent of its involvement, evaluating the functional impact of the lesion, and helping to determine tissue characterization. ${ }^{3}$

\section{References}

1. Centofanti P, Di Rosa E, Deorsola L, Dato GM, Patanè F, La Torre M, et al. Primary cardiac neoplasms: early and late results of surgical treatment in 91 patients. Ann Thorac Surg. 1999;68:1236-41.

2. Burke A, Jeudy J Jr, Virmani R. Cardiac tumors: an update. Heart. 2008;94: 117-23.

3. Sparrow PJ, Kurian JB, Jones TR, Sivananthan MU. MR imaging of cardiac tumors. Radiographics. 2005;25:1255-76.

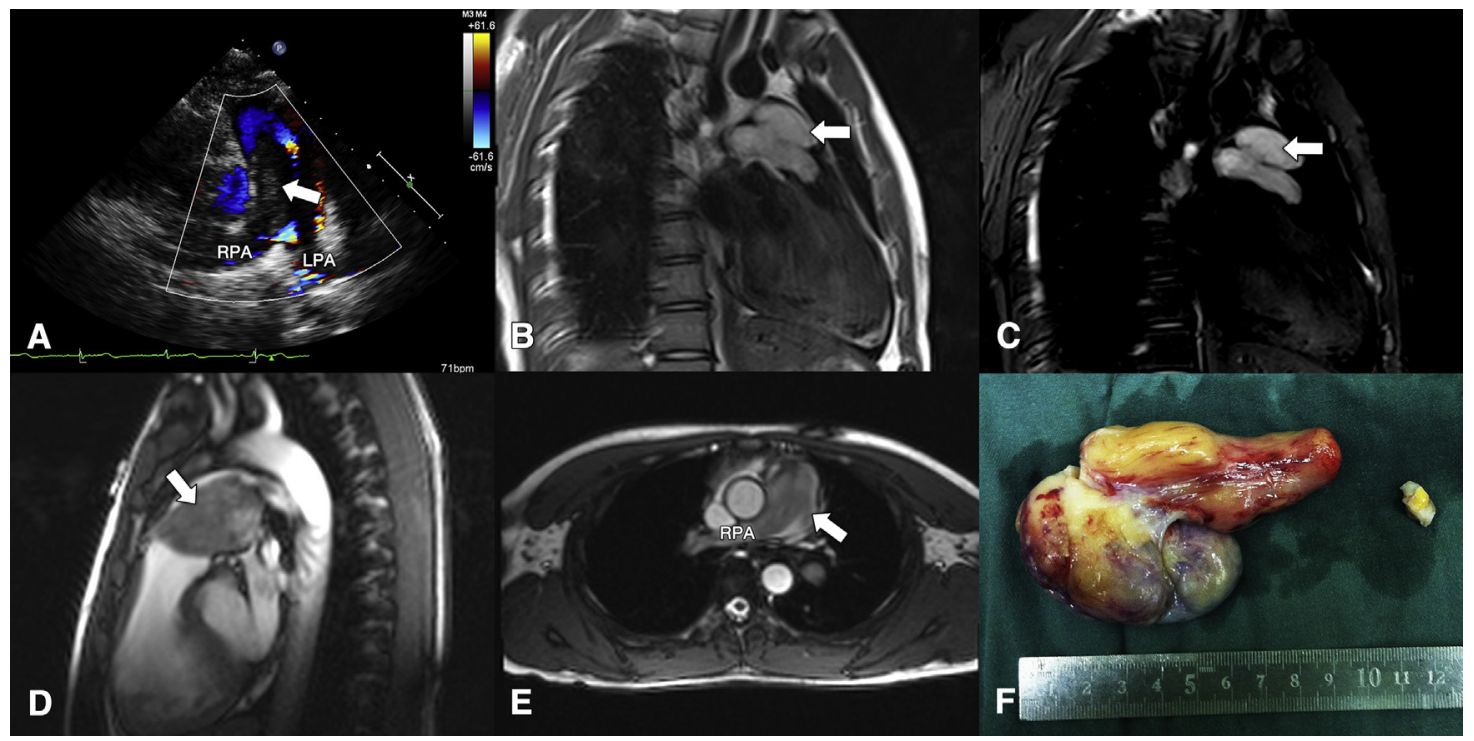

FIGURE 1. Image of primary cardiac synovial sarcoma (white arrow). A, The echocardiogram shows a giant mass in the main pulmonary trunk that protrudes into both the right and left pulmonary arteries. B and C, T2-weighted and fat suppression sagittal images show a giant mass with clear borders located in the main pulmonary trunk. D and E, Contrast-enhanced magnetic resonance imaging (both sagittal and axial views) demonstrated a diffuse, enhanced tumor located in the main pulmonary trunk and 2 bifurcating pulmonary arteries causing obstruction of the pulmonary artery. F, Photograph of the cardiac synovial sarcoma. $R P A$, Right pulmonary artery; $L P A$, left pulmonary artery. 